\title{
Effects of Ebola Virus Disease Outbreak on Bush Meat Enterprise and Environmental Health Risk Behavior Among Households in South-East Nigeria
}

\author{
NwaJesus Anthony Onyekuru' ${ }^{1}$. Chukwuma Otum Ume ${ }^{2}$. \\ Chizoba Perpetua Ezea ${ }^{3}$. Nice Nneoma Chukwuma Ume ${ }^{4}$
}

Accepted: 13 November 2020 / Published online: 22 November 2020

(c) Springer Science+Business Media, LLC, part of Springer Nature 2020

\begin{abstract}
The 2014 disease outbreak in West Africa of the Ebola virus was the longest, largest, deadliest, and most complex epidemic of its kind in history. It was believed to have originated from bushmeat consumption and exhibited sustained human-tohuman transmission. We assessed the effects of the virus outbreak in West Africa on bushmeat enterprise and environmental health risk behaviors among households in Nigeria. We adopted a multistage sampling technique to select 100 respondents. We structured two sets of questionnaires for both bushmeat sellers and consumers. The questionnaire contained information about the respondent's socioeconomic characteristics; perceived causes of the Ebola outbreak; risk behaviors; level of sales; and consumption before, during, and after the Ebola outbreak. We found a significant decrease in the levels of sales and consumption of bushmeat during the outbreak. Consumers perceived touching an infected person, but not eating bushmeat, as a significant mode of Ebola transmission. Although respondents knew about some practices that help to prevent Ebola, they did not practice these to a reasonable extent. We also found that females were $25 \%$ more likely than males to consume bushmeat during the outbreak. Given these findings, we recommend that the government should sensitize people and educate them on risk prevention behaviors they should adopt to prevent the transmission of the Ebola disease.
\end{abstract}

Keywords Ebola $\cdot$ Health risk $\cdot$ Bushmeat $\cdot$ Environmental hygiene $\cdot$ Disease outbreak
Abbreviations
(EVD) Ebola Virus Disease
(LGAs) Local Government Areas

Chukwuma Otum Ume

chukwuma.ume@agrar.uni-giessen.de

Extended author information available on the last page of the article 


\section{Background}

The term bushmeat is commonly used for the meat of terrestrial wild or feral mammals, killed for sustenance or commercial purposes throughout the humid tropics of the Americas, Asia, and Africa (Nasi et al., 2008). Over 500 species are consumed in Sub-Saharan Africa, including red duikers (antelopes), panthers, chimpanzees, gorillas, elephants, African rock pythons, monitor lizards, turtles, porcupines, and bonobos (Fa \& Brown, 2009; Umejei, 2011). There are also numerous edible arthropods such as bees, wasps, grasshoppers, crickets, cockroaches, termites, and dragonflies, as well as cicadas. In fact, the Food and Agriculture Organization (2013) acknowledged that edible insects have the potential to be a food prospect for those who are food insecure.

Bushmeat has long served as an important source of animal protein and a food staple for millions of people across the developing world, most notably in Africa, Latin America, and Asia (Brashares, Golden, Weinbaum, Barrett, \& Okello, 2011). The consumption of bushmeat is an ancient tradition in West Africa, where it is eaten as a protein source in both rural and urban areas (Ordaz-Németh et al., 2017). This is due partly to the low production and supply of conventional protein sources, the unique taste of bushmeat, the fact that it is free to people in rural areas, and that is has luxury appeal among urban dwellers. Thus, people consider it a special delicacy, regardless of tribe, religion, gender, age, or social status. A study by BowenJones, Brown, and Robinson (2002) showed that the bushmeat trade is a large contributor to the economies of West and Central African countries. In places where other types of meat are not available, bushmeat serves as very important sources of both animal protein and income for the rural poor (Bowen-Jones et al., 2002).

However, bushmeat is also a vector of some serious tropical diseases spread to humans (Subramanian, 2012) such as the Ebola Virus Disease (EVD). This viral disease, for which the primary host has been identified as the fruit bat, is a significant public health concern due to its direct connection to bushmeat consumption. Primates are implicated as an intermediate host as they may carry the disease after contracting it from bat droppings or remnants of fruit that infected bats have eaten. Unfortunately, the danger arises when humans contact the infected animal or consume infected bushmeat that has not been prepared properly by cooking at high temperatures between 132.8 and 149 degrees Fahrenheit (Ordaz-Németh et al., 2017). This may well have initiated the EVD outbreak in West Africa in 2014 (FAO, 2014).

A report by the United Nations Development Group (2015) indicated that this outbreak in West Africa was the longest, largest, deadliest, and most complex in history. EVD is believed to have originated from southeastern Guinea and later spread to other West African countries including Sierra Leone, Congo, Liberia, and Nigeria. Unlike past outbreaks, which lasted less than a year, this outbreak persisted for more than 2 years. In 2014, there were 22,859 EVD cases and a total of 9162 deaths in West Africa, specifically in Sierra Leone, Congo, Liberia, and Nigeria (Akani, Dendi, \& Licaluis, 2016). In Nigeria alone, there were 20 laboratory-confirmed EVD cases and 8 deaths (Nigeria Centre for Disease Control, 2020). While increased sensitization concerning the dangers associated with bushmeat has led to 
a reduction in its consumption, some individuals continued to consume it. In this paper, we describe the results of a study designed to determine the effect of the outbreak on the bushmeat enterprise, and the underlying factors that drove the continued consumption of bushmeat during the outbreak, despite public health concerns.

Various studies have been conducted in this area. These relate to the socio-economic impact of the Ebola virus disease on Africa as a whole (Economic Commission for Africa, 2015) and specifically on Guinea, Liberia, and Sierra Leone (United Nations Development Group, 2015); the impact and implications of the Ebola crisis (Rohwerder, 2014); the effects of EVD on bushmeat consumption in Nigeria (Ndem, Maurice, \& Nbana, 2015); and the bushmeat trade in West Africa (Ndem et al., 2015). However, to our knowledge, very little research exists on public health risk behaviors and underlining determinants of people's consumption of bushmeat during the Ebola disease outbreak in Nigeria. Nigeria is the most populous nation in West Africa, and providing this information is vital for policy, regulation, and planning for the prevention and control of the disease, and for assisting vulnerable groups in the country. This information is also vital for advocacy and mass education by relevant stakeholders working in this area. This study, therefore, addresses how the EVD outbreak affected public health risk behaviors of Nigerian households in terms of bushmeat sales and consumption.

Our specific objectives were to:

1. Understand the perception of the respondents concerning bushmeat as a cause of the Ebola disease;

2. Uncover different precautionary measures taken to prevent the spread of the virus and the adoption of such practices during the outbreak; and

3. Assess the determinants of bushmeat consumption during the outbreak.

\section{Materials and Method}

\section{Study Area}

We conducted our study in Nigeria. We chose the Nsukka Agricultural Zone of Enugu State due to the large concentration of bushmeat enterprises and consumerism in the rural, urban, and semi-urban environments of the area. This agricultural zone is made up of three local government areas (LGAs) namely Nsukka, Igboetiti, and UzoUwani (ENADEP, 2012). The area has tropical climates marked by distinct rainy and dry seasons, during which different kinds of wild animals thrive. The vegetation is that of a savannah (resulting from people clearing forest land for cultivation) and people in this area are predominately farmers, who also oftentimes hunt. However, some of the urban areas like Nsukka town have more civil servants and traders who patronize the bushmeat outlets. Bushmeat is sold in this area as it has a high concentration of chop bars, eateries, and restaurants, and the nightlife is vibrant. The map of the Nsukka agricultural zone of Enugu state showing the study areas is presented in Figure 1. 


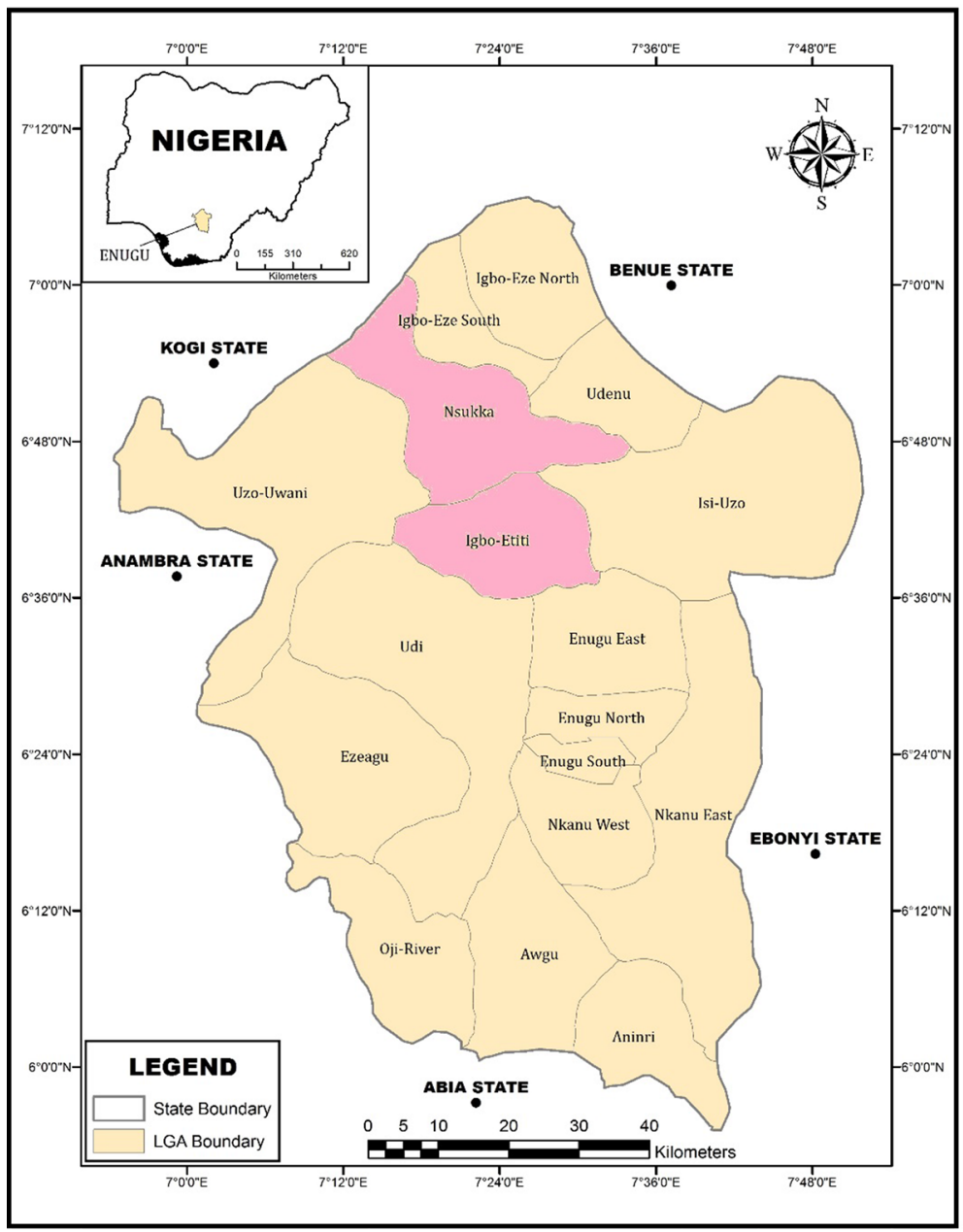

Fig. 1 Map of Enugu State showing the two sample areas

\section{Sampling Procedure and Data Collection}

We adopted a multistage sampling approach to select respondents. Out of the three LGAs in the zone, we randomly selected Nsukka and Igboetiti. We sampled both sellers and consumers of bushmeat. For the sellers, we obtained a comprehensive list of bushmeat traders from the bushmeat trade-union ${ }^{1}$ in the area. From each of

\footnotetext{
1 The Association of Bushmeat Sellers, though not formally registered under the corporate affairs commission of the state, is commonly known as a bushmeat union comprised of sellers of bushmeat in the state. Because the sale of bushmeat is not as common as that of other meats, the sellers know each other well and form a cartel, where pricing is set and other hunting decisions are made.
} 
the Nsukka and Igboetiti LGA lists, we randomly selected 20 sellers, making a sample of 40 sellers.

We obtained an aggregated list of bushmeat consumers from the sellers and from this list we randomly selected 30 bushmeat consumers from the two LGAs, making it a total of 60 consumers. We collected quantitative data from trade union documents and through interviews conducted in person with the aid of a semi-structured questionnaire. From the trade union documents, we collected data on the amount of bushmeat sold and consumed before, during, and after the EVD outbreak. We conducted interviews in June-July 2014 during the outbreak, and again between February-April 2016, after it. We collected demographic and socioeconomic data from both the traders and consumers, such as age, gender, marital status, education level, and income. We also assessed respondents' perception on the mode of EVD transmission, specifically through preventive measures like the use of gloves when in contact with other people, washing hands with sanitizer, avoidance of bushmeat, cooking bushmeat properly, avoiding contact with others, and abstaining from any type of meat; and if they perceived other measures as preventive, like eating bitter kola, a common wild fruit thought to have medicinal properties against viral diseases (Starin, 2013) and praying. We provided a list of the perceptions of modes of EVD transmission and possible preventive measures and instructed participants to check options that applied to them. Paper questionnaires were administered in person to the consumers and traders at the bushmeat bars. Interview time took an average of $1 \mathrm{~h}$ per respondent. Participants were also allowed to include additional measures not included on our list. We also included potentially harmful or superstitious practices that individuals adopted such as bathing with salt and disinfecting utensils with 'sniper' chemical. ${ }^{2}$ For the level of sales (measured by the average number of plates of bushmeat sold), we obtained documents from the bushmeat sellers union showing the average plates of bushmeat sold by the sampled sellers before, during, and after the EVD outbreak. A comprehensive list of the variables and their associated measures is presented in Table 1 .

We used research assistants and translators fluent in the local language (Nsukka language) to interview the respondents. The research assistants were also bushmeat consumers and thus could easily engage with the study's respondents and could converse with both sellers and fellow consumers.

\section{Data Analysis}

We analyzed data using mean score techniques, $t$ test results, and binomial logit models. We used Likert-type scales to measure (1) the respondent's perception of bushmeat as a cause of the Ebola disease, (2) the different precautionary measures expected to be taken to prevent the spread, and (3) the adoption of such practices

\footnotetext{
${ }^{2}$ Sniper chemical is an insecticide containing the active ingredient Bifenthrin. It is used only for plants and can be applied on plant foliage and soil to control pests. Just like other pesticides, sniper is dangerous to human beings.
} 
Table 1 Description of variables and scale of measurement

\begin{tabular}{ll}
\hline Variable & Values/measure \\
\hline Sex & Female $=1$, male $=0$ \\
Household size & Number of members \\
Age & Number of years \\
Marital status & $1=$ single, married $=0$ \\
Years spent in school & Years \\
Monthly income & in Nigeria Naira \\
Distance to the nearest location & Kilometres \\
Food consumption status & Number of times the respondent eats in a day \\
Number of selling locations & Numbers \\
Perceived risk of bushmeat consumption & $1=$ Risky, $0=$ Not a risk \\
Amount of bushmeat sales & Number of plates of bushmeat sold in a month \\
Amount of bushmeat consumed & Frequency of consumption in a month \\
\hline
\end{tabular}

during an outbreak. Specifically, we rated Strongly Agree as 4 points, Agree as 3 points, Disagree as 2 points, and Strongly Disagree as 1 point. The mean was 2.5 $(4+3+2+1=10 / 4)$. Scores under 2.5 were not considered to be perceived as a preventive measure.

We used $t$-test analyses to examine statistical differences between the sales and consumption of bushmeat before and during the Ebola disease outbreak in Nigeria. To test for the normality of the variables, we employed the Shapiro W test. We obtained $p$ values less than the usual 0.05 for all the variables apart from the sales and consumption variables during the Ebola crisis. This meant that the sales and consumption figures during the Ebola crisis were not normally distributed. To address this, we logged the affected variables and conducted a lognormal test which provided a normal distribution result. We used a generalized linear model with binomial model error structure and logit link function (McCullagh \& Nelder, 1989) to determine the likelihood of consumption of bushmeat during the Ebola outbreak. Our dependent variable was given a value of (1) if the respondent consumed bushmeat during the Ebola disease outbreak, and (0) if the respondent did not. Reasons for consuming bushmeat or not could be related to the respondent's demographic or socioeconomic characteristics (i.e., family size, gender, age, level of education, monthly income, household size). Marital status was also introduced into the model as it has been often been associated with risk aversion, taking precautions, and reducing eating outside of the house (Han et al., 2014). Control predictors added to the model included the number of selling spots, ${ }^{3}$ their perceived risk of bushmeat consumption, and the distance from their home to the nearest selling spot. We ran a full-null model comparison using STATA 15. The marginal effect of the variables was also used to determine the likelihood of consumption of bushmeat during

\footnotetext{
3 Selling spots are locations or shops or bars where prepared bushmeat are bought and sold. They are usually known as 'Busbar'.
} 
Table 2 Mean monthly sales and consumption before, during, and after the Ebola outbreak

\begin{tabular}{|c|c|c|c|c|c|c|}
\hline & \multicolumn{3}{|c|}{$\begin{array}{l}\text { SALES } \\
\text { (\# of plates of bushmeat sold in a } \\
\text { month) }\end{array}$} & \multicolumn{3}{|c|}{$\begin{array}{l}\text { CONSUMPTION } \\
\text { (frequency of consumption in a } \\
\text { month) }\end{array}$} \\
\hline & Minimum & Maximum & Mean & Minimum & Maximum & Mean \\
\hline Before Ebola outbreak & 150 & 600 & 192.5 & 2.0 & 50.0 & 12.28 \\
\hline During Ebola outbreak & 0 & 450 & 111 & 0.0 & 60.0 & 8.23 \\
\hline After Ebola outbreak & 0 & 510 & 163.0 & 0.0 & 50.0 & 11.83 \\
\hline
\end{tabular}

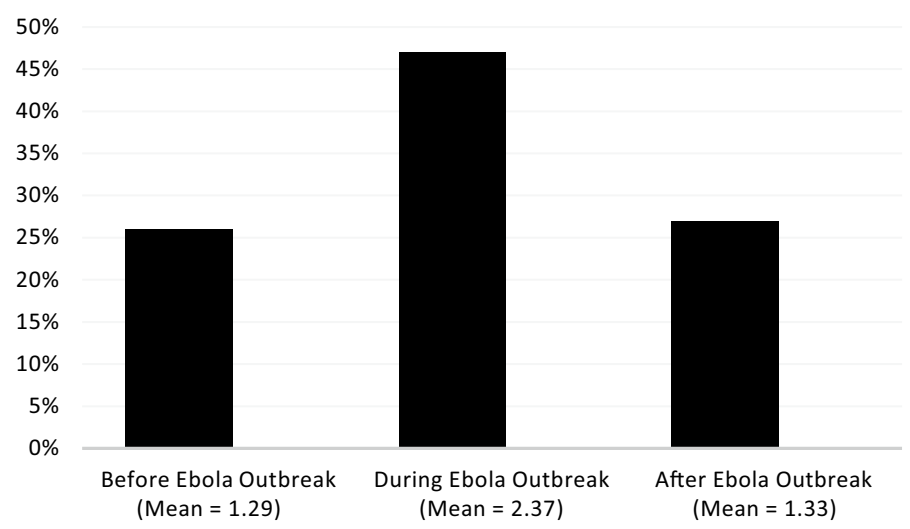

Fig. 2 Mean scores of respondents' perception of bushmeat as a cause of the Ebola Disease before, during, and after the Ebola outbreak. Decision rule: If mean score $<2.50$, then reject that they perceived bushmeat as a cause of Ebola, and if $\geq 2.50$, accept.

the Ebola outbreak. The variables used in the logit model analysis their descriptions, and their expected values are presented in Table 1. We log-transformed the variables income, family size, and age, as they had highly skewed distributions. Also, we used STATA15 to run the regression analysis where multicollinearity was controlled automatically, and variables such as spending level and primary occupation were dropped from the model. The Spearman test for correlation among predictors also confirmed the multicollinearity of these variables, supporting our decision to exclude them. 


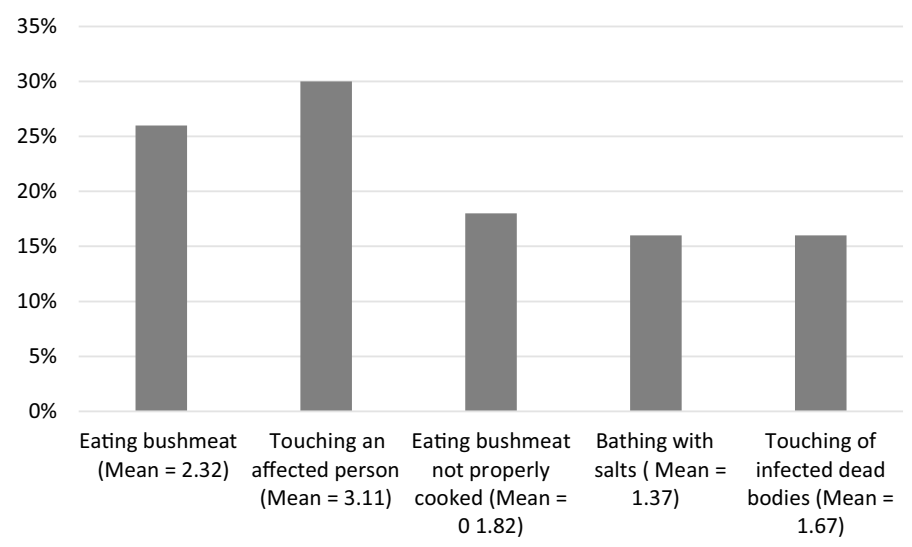

Fig. 3 Mean scores of respondents on their perceived modes of Ebola transmission. Decision rule: If mean score $<2.50$, then reject that they perceived bushmeat as a cause of Ebola, and if $\geq 2.50$, accept.

\section{Results}

\section{Perception of Bushmeat as a Cause of the Ebola Virus Disease}

The effects of the outbreak on the actual sales and consumption of bushmeat before, during, and after the outbreak are presented in Table 2. We used $t$ tests to determine if differences noted were statistically different from zero.

The consumers' perception of bushmeat as a cause of the Ebola disease before, during, and after the Ebola outbreak is presented in Figure 2. The results show that more than half of the respondents did not perceive bushmeat as a cause of Ebola at any of these periods. Though their perception of bushmeat as the cause of the Ebola disease was highest during the outbreak, it did not reach the cut off value of 2.50 for us to consider it as a cause of Ebola disease. As shown in Figure 1, only $26 \%$ of respondents believed eating bushmeat was the cause of the virus before the outbreak; this barely increased to $27 \%$ during the outbreak, but rose to $47 \%$ after it. Similarly, as presented in Figure 3,30\% of the respondents strongly agreed that touching an infected person was a significant mode of Ebola virus transmission, as it was the only variable with a mean score of 3.43 (greater than our cutoff of 2.50). Although the mean score for eating bushmeat was high (2.32), it did not reach the cut off of 2.50 for us to consider it as a perceived cause of the Ebola disease.

Our study further investigated the effects of the outbreak on the difference in the percentage of actual sales and consumption rates of bushmeat in the area. As indicated in Table 2, we found that the sale of bushmeat was high before the outbreak, as was the rate of consumption. However, during the Ebola outbreak, there was a sharp drop in sales and consumption, such that some of the sellers recorded no sales whatsoever, and consumers reported that they did not consume any bushmeat. It also shows that even after the outbreak, some sellers and consumers did not recover from the shock of the epidemic, as they continued to report they did not sell or consume any bushmeat. 
Table 3 A $t$ test comparison of mean consumptions and sales

\begin{tabular}{llr}
\hline & $t(d f)$ & $p$ \\
\hline Sales before and during & $3.445(40)$ & .001 \\
Sales during and after & $5.444(40)$ & $<.001$ \\
Sales before and after & $4.005(40)$ & $<.001$ \\
Consumption before and during & $4.995(60)$ & $<.001$ \\
Consumption during and after & $4.558(60)$ & $<.001$ \\
Consumption before and after & $1.101(60)$ & .275 \\
\hline
\end{tabular}

Table 4 Practices believed to be prevention of the spread of Ebola by the respondents

\begin{tabular}{lll}
\hline Practices & Mean & Standard deviation \\
\hline Use of gloves when having contact with people & $3.440^{\mathrm{a}}$ & 1.0281 \\
Use of gloves when preparing bushmeat for cooking & 2.080 & 1.1693 \\
Washing hands with hand sanitizer & $3.600^{\mathrm{a}}$ & 0.8040 \\
Avoidance of any bushmeat & $3.580^{\mathrm{a}}$ & 0.8667 \\
Cooking bushmeat properly & $3.030^{\mathrm{a}}$ & 1.1499 \\
Eating bitter kola & $2.850^{\mathrm{a}}$ & 1.2503 \\
Avoidance of any sick person & $2.500^{\mathrm{a}}$ & 1.1763 \\
Praying & $2.840^{\mathrm{a}}$ & 1.1346 \\
Avoiding contact with any person & $3.080^{\mathrm{a}}$ & 1.2365 \\
Disinfecting utensils with 'sniper' chemical & 1.970 & 0.9477 \\
Abstinence from any type of meat & $2.510^{\mathrm{a}}$ & 1.2988 \\
\hline
\end{tabular}

${ }^{a}$ Variables with mean greater than 2.50 showed participants strongly accepted this as a practice for the prevention of Ebola

${ }^{\mathrm{b}}$ False and potentially harmful measures that were adopted dues to unsubstantiated rumors

The results of the $t$ tests conducted (see Table 3) showed that there was a statistical difference in both the sales and the consumption of bushmeat between before and during the EVD outbreak, and also between during and after the EVD outbreak. We also observed a statistical difference between sales, but not consumption, of bushmeat before and after the crisis.

\section{Public Health Risk Behaviors Exhibited by Consumers and Sellers During the EVD Outbreak}

Our results (see Tables 4 and 5) show that respondents were aware of potentially preventive measures like use of gloves when in contact with other people, washing hands with sanitizer, avoidance of bushmeat, avoiding contact with others, and abstinence from any type of bushmeat. However, they were not aware of preventive measures like the use of gloves while preparing bushmeat, and then washing utensils with disinfectants if they had been used in bushmeat preparation. Although respondents knew about some of these preventive measures, Table 5 shows that most of 
Table 5 Measures perceived by the respondents as preventive

\begin{tabular}{|c|c|c|c|}
\hline Practices adopted & Mean & $\%$ & $\begin{array}{l}\text { Standard } \\
\text { devia- } \\
\text { tion }\end{array}$ \\
\hline Bathing with salt ${ }^{\mathrm{a}}$ & 1.68 & 33.6 & 0.94 \\
\hline Use of gloves when having contact with people & 1.57 & 31.4 & 0.92 \\
\hline Use of gloves when preparing bushmeat for cooking & 1.60 & 32 & 4.22 \\
\hline Washing hands with hand sanitizer & 2.30 & 46 & 1.29 \\
\hline Avoidance of any bushmeat & 2.23 & 44.6 & 1.34 \\
\hline Cooking bushmeat properly & 2.05 & 41 & 1.29 \\
\hline Eating bitter kola & 1.59 & 31.8 & 1.07 \\
\hline Avoidance of any sick person & 1.73 & 34.6 & 1.08 \\
\hline Praying & 2.08 & 41.6 & 1.24 \\
\hline Avoiding contact with any person & 1.84 & 36.8 & 1.16 \\
\hline Disinfecting utensils with 'sniper' chemical ${ }^{\mathrm{a}}$ & 1.52 & 30.4 & 0.94 \\
\hline Abstinence from any type of meat ${ }^{\mathrm{a}}$ & 1.19 & 23.8 & 0.50 \\
\hline
\end{tabular}

Source Field survey, 2016

${ }^{a}$ False and potentially harmful measures that were adopted dues to unsubstantiated rumors

Table 6 Summary of logistic regression analysis

\begin{tabular}{lllll}
\hline Demographic and Socioeconomic Characteristics & Coefficient & $p$ & Marginal effect & $p>|z|$ \\
\hline Gender & 6.35 & $0.00 * * *$ & 0.37 & $0.01^{* * *}$ \\
Log age & 1.03 & 0.41 & 0.01 & 0.41 \\
Marital status & 0.50 & 0.38 & -0.13 & 0.37 \\
Log years spent in school & 1.06 & 0.25 & 0.01 & 0.25 \\
Family Size & 0.95 & 0.72 & -0.01 & 0.72 \\
Perceived risk of bushmeat consumption & 0.30 & $0.02 * *$ & -0.23 & $0.01 * *$ \\
Distance to the nearest spot & 0.98 & 0.59 & -0.01 & 0.59 \\
food consumption status & 1.95 & $0.01 * *$ & 0.13 & $0.01 * * *$ \\
Number of selling locations & 1.63 & $0.08 *$ & 0.09 & $0.08^{*}$ \\
\hline
\end{tabular}

$* p<0.05 . * * p<0.01 . * * * p<0.001$.

them did not practice them to a reasonable extent, insofar as none of the risk behaviors had a mean score above 2.50. We also observed that some of the respondents began adopting potentially superstitious measures, such as abstinence from any type of meat (23.8\%), bathing with salt (33.6\%), eating bitter kola (31.8\%), and disinfecting utensils with 'sniper' chemical (30.4\%).

During the outbreak, some consumers reduced, while other maintained, their consumption of bushmeat. We ran a logistic regression to assess whether socioeconomic characteristics affected respondents' consumption during the Ebola outbreak. We used the marginal effect to measure the likelihood that these demographic or socioeconomic characteristics could determine whether the respondent consumed 
bushmeat or not during the outbreak. These results are presented in Table 6. The results show that only gender, perceived risk of bushmeat consumption, food consumption status, and the number of selling spots in the location were statistically significant variables affecting bushmeat consumption during the outbreak. We carried out a full-null model comparison and found that the predictors were significantly $(p=0.03)$ different from zero, suggesting fitness of the entire model.

\section{Discussion}

Our study's findings confirmed that the majority of our respondents did not agree that consuming bushmeat is a possible cause of Ebola. According to Bifarin, Ajibola, and Fadiyimu, (2008), bushmeat in West Africa has occupied an important position on the menu of most rural dwellers for centuries. The majority of rural dwellers believe bushmeat is a symbol that represents a means by which to connect with their early ancestors (Bowen-Jones et al., 2002). This may make it difficult for them to believe that the consumption of this meat could be a potential source of infection. Even though most of our study respondents did not perceive consuming bushmeat as a possible cause of Ebola, the observed reduction in consumption rate might not be an intentional act of refraining by people, but is more likely due to the reduction in availability, given that the sale of bushmeat dropped significantly during the crisis. Thus, individuals had no choice but to reduce their consumption. In general, this result is congruent with the findings of ENADEP (2012) and Ndem, Maurice, and Nbana (2015), which state that both the ban on bushmeat and the awareness campaign put forward by the government about the risks associated with the consumption of bushmeat led to a reduction in both sales and consumption. Ordaz-Németh et al. (2017) also identified perceived risk as one factor influencing the frequency of bushmeat consumption during the West African Ebola crisis. In addition, and consistent with our results, Ordaz-Németh et al. (2017) listed reduced household income as another influential factor lessening consumption. According to Ordaz-Németh et al. (2017), monetary costs had a greater influence on consumption habits than perceived risk.

According to the public psychological Health Belief Model proposed by OrdazNémeth et al. (2017), people will engage in preventive behavior once they feel vulnerable to a health condition that threatens their life. The theory further argues that if individuals perceive that the costs of engaging in preventive behavior exceed the benefits, they will not likely exhibit and maintain the preventive behavior. In other words, it is key that the public perceives the benefits of the desirable behavior to achieve the public health goals of prevention. Thus, there is a need for the use of different media to drive home the message of EVD and bushmeat consumption, especially in the rural areas of the developing world. Attempts to change behavior, therefore, should take into account these factors. As another example, Whitcraft et al. (2014) reported substantial drops in shark fin demand in China after launching a large scale, culturally sensitive, and celebrity-driven multimedia campaign. This showed how mass communication messages that appeal to the rural populace 
distributed through local town public figures, town hall meetings, and major rural festivals can be effective at changing behaviors.

Apart from household income and perceptions, there are other pertinent socioeconomic factors that influence the respondent's decision to consume bushmeat during the EVD crisis. Our study's results showed that families with larger households, those with longer distances to the nearest sales location, and married individuals reduced their frequency of consumption during the study period. Conversely, we found that these other groups consumed more bushmeat during the outbreak: females, older persons, more educated individuals, not risk-averse persons, those with an increased number of selling spots near their home, and those with higher food consumption status (larger diversity of food items).

Our study found that only gender, perceived risk of infected bushmeat consumption, food consumption status, and number of selling spots were statistically significant predictors for the consumption of bushmeat. Gender significantly influenced the decision to eat or not eat during the outbreak: females consumed more bushmeat during the crisis, which invariably suggests that females are more likely to contract the disease through the consumption of bushmeat. It is this increase in females' consumption of bushmeat that could have accounted for the rise in the maximum quantity consumed from 50 plates of bushmeat before and after the outbreak to as much as 60 plates during the EVD crises (see Table 2). This is in line with findings reported by Fawole, Bamiselu, Adewuyi, and Nguku (2018) who studied gender dimensions to the Ebola outbreak in Nigeria and reported that women made up $55 \%$ of Ebola cases and $56.6 \%$ of contacts traced. This does not, however, directly suggest that bushmeat consumption led to more infection, but that females are less risk-averse with regard to public health consequences. Fawole et al., (2018) further reported a $2.2 \%$ fatality rate among females, and $2.3 \%$ fatality rate among males. These findings are critical in the formulation of health care policies and planning. There is a need to ensure that women have access to appropriate information and services. This is particularly important because women, due to their caregiving roles, are exposed occupationally and domestically. Disease outbreaks such as COVID-19 have also shown similar sex-differentiated impacts. Although genderdisaggregated data for COVID-19 show that males and females so far are affected alike, there have been reports that show sex differences (although in this case males being more affected) in terms of mortality and vulnerability to the disease (Wenham, Smith, \& Morgan, 2020). There is, therefore, the need for strategic policies and prevention efforts that will address potential sex differences in disease outbreaks.

The dummy variable measuring perceived risk of bushmeat consumption conformed to a priori expectations as the sign of the coefficient was negative (see Table 6). This suggests that individuals who perceive bushmeat to be a transmission channel for the EVD tend to minimize their level of consumption or even that they avoided eating bushmeat altogether. This supports the argument by OrdazNémeth et al. (2017) that bushmeat consumers will not eat bushmeat if they believe that they can contract Ebola from doing so.

The high death rate associated with the Ebola disease in West Africa has been estimated between 25 and 90\% (World Health Organization, 2020). Our findings showed that people deliberately altered some of their customary life activities 
regarding bushmeat consumption (see Table 5). However, in the case of the Lassa fever in Nigeria, the World Health Organization (2019) analysis of emergency preparedness showed that most of the individuals did not take the disease seriously, as they did not feel it was real. This may be connected to the fact that up to $80 \%$ of the persons infected with the Lassa virus were found to be asymptomatic (World Health Organization, 2019). That is also the case regarding the 2019/2020 COVID-19 virus situation, in which many seem to believe that the virus is not real and would likely not affect them personally (Ebuka \& Nike, 2020; OakTV, 2020). These assumptions are detrimental to primary prevention strategies and stress that there is work to do to encourage public awareness of these outbreaks. In a report by Ogoanah and Oboh (2017), massive public enlightenment by the government on the fatality potential of the EDV led to an adoption of preventive measures by citizens (over $30 \%$ of the respondents began following the preventive guidelines). However, we observed that this public enlightenment unfortunately also exacerbated people's anxiety and the misinformation to which they were exposed. This anxiety and misinformation led to the circulation of unsubstantiated rumors and the adoption of potentially harmful measures such as bathing with salt water. This in turn led to the death of more people than was caused by the Ebola virus (BBC, 2014). Therefore, there is a need for experts to take great care of what they communicate with the public and how they communicate it.

\section{Conclusion}

The 2014 Ebola Virus Disease outbreak in West Africa affected different economic sectors, specifically the bushmeat enterprise. The EVD scare and the awareness that followed the outbreak resulted in a reduction in bushmeat consumption in Nigeria. Despite this, some individuals continued consuming bushmeat during this period. We strove to empirically ascertain the effect of the outbreak on the bushmeat enterprise and the underlining factors that were driving the consumption of bushmeat during this period, regardless of the public health concerns at the time.

The results of our study showed that there was a statistically significant drop in the levels of sales and consumption of bushmeat during the outbreak. A greater proportion of consumers did not agree that bushmeat consumption was a cause of Ebola, but did agree that "touching an infected person" was a main mode of EVD transmission. Although respondents knew about some practices that help to prevent EVD, they did not practice them to any reasonable extent. These findings underscore the significance of providing adequate and first-hand information about the critical nature and consequential risk of acquiring this potentially fatal viral disease. Our study showed that when individuals begin to understand the severity of a pandemic, they are more likely to adjust their behaviors accordingly.

Authors' Contributions CE collected the data, wrote the background. ANO wrote the methodology, analysed the data, presented the results and supervised the study; CU interpreted the results and prepared 
the manuscript. NNC proofread the work, reanalysed the data to ensure accuracy, and edited the entire manuscript.

Funding No funding was obtained from any source for this study.

Availability of Data and Material The datasets generated and analysed during the current study are not publicly available but are available at the corresponding author's request.

\section{Compliance With Ethical Standards}

Conflict of interest The authors declare that they have no competing interests.

Research Involving Human Participants and/or Animals All procedures performed in studies involving human participants were in accordance with the ethical standards of the institutional and/or national research committee and with the 1964 Helsinki declaration and its later amendments or comparable ethical standards."

Informed Consent Informed consent was obtained from all individual participants included in the study.

\section{References}

Akani, G. C., Dendi, D., \& Licaluis, E. (2016). Ebola Virus effect on bushmeat trade in West Africa. African Journal of Ecology, 53(4), 613-615. https://doi.org/10.111iage12231.

BBC. (2014). Ebola risk from air travel low-WHO. Retrieved 10 April 2020, from https://www.bbc. com/news/world-africa-287924422.

Bifarin, J. O., Ajibola, M. E., \& Fadiyimu, A. A. (2008). Analysis of marketing bush meat in Idanre local government area of Ondo state. Nigeria. African Journal of Agricultural Research, 3(10), 667-671.

Bowen-Jones, E., Brown, D., \& Robinson,E. (2002). Assessment of the solution oriented research neede to promote a more sustainable bushmeat trade in Central and West Africa. Retrieved 12 April 2020, from https://www.odi.org/sites/odi.org.uk/files/odi-assets/publications-opinion-files/3894.pdff.

Brashares, J., Golden, C., Weinbaum, K., Barrett, C., \& Okello, G. (2011). Economic and geographic drivers of wildlife consumption in rural Africa. Proceedings of the National Academy of Sciences, 108(34), 13931-13936. https://doi.org/10.1073/pnas.10115261088.

Ebuka and Nike. (2020). Nigeria Faces Possible Covid-19 Second Wave but Has Let Guard Down. African peace Magazine. Retrieved 17 November 2020, from https://africanpeace.org/nigeria-faces -possible-covid-19-second-wave-but-has-let-guard-down/.

Economic Commission for Africa. (2015). Impact of Ebola on Africa. Retrieved 12 April 2020, from https://www.uneca.org/sites/default/files/PublicationFiles/eca_ebola_report_final_eng_0.pdf.

ENADEP. (2012). Enugu State Agricultural Development Programme: Annual Report p27 (Offline).

Fa, J., \& Brown, D. (2009). Impacts of hunting on mammals in African tropical moist forests: A review and synthesis. Mammal Review, 39(4), 231-264. https://doi.org/10.1111/j.1365-2907.2009.00149.x.

FAO. (2014). Frequently asked questions on Ebola virus disease: FAO in Emergencies. Retrieved 11 April 2020, from http://www.fao.org/emergencies/fao-in-action/stories/stories-detail/en/c/251862//.

Fawole, O. I., Bamiselu, O. F., Adewuyi, P. A., \& Nguku, P. M. (2018). Gender dimensions to the Ebola outbreak in Nigeria 2016. Annals of African Medicine, 15, 7-13.

Food and Agriculture Organization. (2013). Edible insects: Future prospects for food and feed security. FAO Forestry Paper 171. Food and Agriculture Organization of the United Nations Rome, 2013. http://www.fao.org/3/i3253e/i3253e.pdf.

Han, K., Park, E., Kim, J., et al. (2014). Is marital status associated with quality of life? Health and Quality of Life Outcomes, 12, 109. https://doi.org/10.1186/s12955-014-0109-0.

McCullagh, P., \& Nelder, J. A. (1989). Generalized linear models (2nd ed.). London: Chapman and Hall. https://doi.org/10.1007/978-1-4899-3242-66.

Nasi, R., Brown, D., Wilkie, D., Bennett, E., Tutin, C., Van Tol, G., \& Christophersen, T. (2008). Conservation and use of wildlife-based resources: The bushmeat crisis. CBD Technical Series no. 
33. Secretariat of the Convention on Biological Diversity and Center for International Forestry Research (CIFOR). pp. 1-50. Retrieved January 17 2016, from http://re.indiaenvironmentportal.org. in/files/Conservation\%20and\%20use\%20of\%20wildlife-based\%20resources.pdff.

Ndem, S., Maurice, E., \& Nbana, D. D. (2015). Effect of Ebola virus disease on bushmeat consumption in Calabar Muncipal. International Journal of Business \& Law Research, 3(3), 32-48.

Nigeria Centre for Disease Control. (2020). EBOLA. Retrieved 7 November 2020, from https://ncdc.gov. $\mathrm{ng} /$ diseases/info/E.

OakTV. (2020). Why some Nigerians don't believe coronavirus exists. Retrieved 27 July 2020, from https ://www.youtube.com/watch?v=Fo6gzCUx5lc.

Ogoanah, S. O., \& Oboh, I. P. (2017). Effect of Ebola virus on bushmeat sales in Benin City, Edo State. Nigeria. African Scientist, 18(2), 129-134.

Ordaz-Németh, I., Arandjelovic, M., Boesch, L., Gatiso, T., Grimes, T., Kuehl, H. S., et al. (2017). The socio-economic drivers of bushmeat consumption during the West African Ebola crisis. PLOS Neglected Tropical Diseases, 11(3), e0005450. https://doi.org/10.1371/journal.pntd.0005450.

Rohwerder, B. (2014). Impact and implications of Ebola crisis. Applied knowledge \& law services. www. gsdrc.org.

Starin, D. (2013). Kola nut: so much more than just a nut. Journal of the Royal Society of Medicine, 106(12), 510-512. https://doi.org/10.1177/0141076813507708.

Subramanian, M. (2012). Zoonotic disease risk and the bushmeat trade: Assessing awareness among hunters and traders in Sierra Leone. EcoHealth, 9(4), 471-482. https://doi.org/10.1007/s1039 3-012-0807-1.

Umejei, E. (2011). Bushmeat sellers protest low patronage. Daily Independence. Retreived from http:// www.Independentngonline.com/Dailyindependent/Article.aspx id=36382.

United Nations Development Group. (2015). Socio Economic impact of Ebola virus Disease in West African Countries: A call for national and regional containment, recovery and prevention. Retrieved 10 April 2020, from https://www.undp.org/content/dam/rba/docs/Reports/ebola-west-africa.pdff.

Wenham, C., Smith, J., \& Morgan, R. (2020). COVID-19: The gendered impacts of the outbreak. The Lancet, 395(10227), 846-848. https://doi.org/10.1016/s0140-6736(20)30526-2.

Whitcraft, S., Hofford, A., Hilton, P., O’Malley, M., Jaiteh, V. and P. Knights (2014). Evidence of declines in shark fin demand: China. Wild Aid. Retrieved 10 April 2020, from https://www.researchgate.net/ publication/282568010_Evidence_of_declines_in_shark_fin_demand_Chinaa.

World Health Organization (2019). Lassa Fever_-Nigeria: Emergencies preparedness, response. Retrieved 10 April 2020, from https://www.who.int/csr/don/20-february-2020-lassa-fever-nigeria/ en/.

World Health Organization (2020). Ebola virus disease. Retrieved 10 April 2020, from https://www.who. int/news-room/fact-sheets/detail/ebola-virus-disease.

Publisher's Note Springer Nature remains neutral with regard to jurisdictional claims in published maps and institutional affiliations.

\section{Affiliations}

\section{NwaJesus Anthony Onyekuru ${ }^{1}$ Chukwuma Otum Ume ${ }^{2}$ D Chizoba Perpetua Ezea ${ }^{3}$. Nice Nneoma Chukwuma Ume ${ }^{4}$}

NwaJesus Anthony Onyekuru

anthony.onyekurur@unn.edu.ng

Chizoba Perpetua Ezea

chizoba.ezea@warwick.ac.uk

Nice Nneoma Chukwuma Ume

nice.chukwuma@tm.uni-giessen.de

1 Resource and Environmental Policy Research Centre, University of Nigeria, Nsukka, Nigeria 
2 Institute for Agricultural Policy and Market Research, Justus Liebig University, Giessen, Germany

3 School of Life Sciences, University of Warwick, Coventry, UK

4 Transition management, Justus Liebig University, Giessen, Germany 